This is an electronic reprint of the original article. This reprint may differ from the original in pagination and typographic detail.

Author(s): Ngwayuh, Elvis Nshom

Title: $\quad$ Predictors of Finnish Adolescent's Prejudice towards Russian Immigrants and the Effect of Intergroup Contact

Year: $\quad 2016$

Version:

Please cite the original version:

Ngwayuh, E. N. (2016). Predictors of Finnish Adolescent's Prejudice towards Russian Immigrants and the Effect of Intergroup Contact. Journal of Intercultural Communication Research, 45(1), 31-44. https://doi.org/10.1080/17475759.2015.1136347

All material supplied via JYX is protected by copyright and other intellectual property rights, and duplication or sale of all or part of any of the repository collections is not permitted, except that material may be duplicated by you for your research use or educational purposes in electronic or print form. You must obtain permission for any other use. Electronic or print copies may not be offered, whether for sale or otherwise to anyone who is not an authorised user. 
PREDICTORS OF FINNISH ADOLESCENT'S PREJUDICE TOWARDS RUSSIAN IMMIGRANTS AND THE ROLE OF INTERGROUP CONTACT

\author{
by \\ Nshom E. (2015) \\ Journal of Intercultural Communication Research, 45, 31-44
}

Reproduced with kind permission by the publisher. 
Nshom Elvis (2015), Predictors of Finnish adolescent's prejudice towards Russian immigrants and the role of intergroup contact. Journal of Intercultural Communication Research, 45 31-44.

\title{
Predictors of Finnish Adolescent's Prejudice towards Russian Immigrants and the Effect of Intergroup Contact
}

\author{
Elvis Nshom
}

Department of language and communication studies

University of Jyväskylä, Jyväskylä Finland

\begin{abstract}
This study examined perceived threat as a predictor of Finnish adolescent's prejudice towards Russian immigrants. Moreover, since Russian immigrants represent the largest immigrant group in Eastern Finland, this study also explored the relationship between intergroup contact, threat, and prejudice. The sample consisted of 305 Finnish adolescents ranging from 11 to 19 years old. Results showed threat to be a significant predictor of prejudice towards Russian immigrants in Eastern Finland. Individually, negative stereotype was found to be the only threat that significantly predicted prejudice towards Russian immigrants. Realistic and symbolic threats were not important to the attitudes of Finnish adolescents towards Russian immigrants. Moreover, there was no significant relationship between intergroup contact, prejudice, and threat (realistic threat, symbolic threat, and negative stereotype). Implications are also discussed.
\end{abstract}

Keywords: prejudice; Finland; Russian immigrants; immigration; integrated threat. 


\section{Introduction}

Europe has witnessed a tremendous increase in immigration within the last two decades (Meuleman, Davidov \& Billiet, 2009) and Finland is no exception. This is mostly because Finland compared to countries like Britain, France, Germany, and Italy has traditionally been a homogeneous society and highly excluded from mass immigration (Ervasti, 2004; Jasinskaja-Lahti, 2000; Jasinskaja-Lahti \& Liebkind, 2001; Kyntäjä, 1997). Even though, immigration in Finland has been on the increase since the $1990 \mathrm{~s}$, the immigrant population of about 200,000 still constitutes only about $2-3 \%$ of the total population (Statistics Finland, 2014). Among the various immigrant groups and an immigrant population of over 200,000, Russian immigrants have always been the largest until 2011 when they became the second largest immigrant group in Finland after Estonians. However, the Russian speaking community still remains the largest immigrant community in Finland (Helsingin Sanomat, 2011).

Unfortunately, it has been reported that Russian speaking immigrants in Finland are often victims of prejudice and discrimination and also feel psychologically and emotionally alienated more than any other immigrant groups (Jaakkola, 2000; Protassova, 2008). This has also been noted internationally by the European Commission against Racism and Intolerance, (ECRI) who recommended that Finnish authorities pay much more attention to the specific problems of disadvantage and discrimination faced by Russian speaking communities in Finland and that action be taken to fight negative societal attitudes and intolerance toward members of the Russian speaking community, which is said to have intensified due to lack of determined action on the part of Finnish authorities (JasinskajaLahti \& Liebkind, 2001). Reports indicate Russian speakers have been targets of violence; Russian speakers have suffered from racial harassment, and bullying of Russian speaking children at school has also been reported. Attention has also been drawn to anti-Russian materials on the internet and media inciting hatred and to the use of derogatory expressions to refer to Russian immigrants (ECRI, 2007). 
Despite the numerical (see Statistics Finland, 2014) and historical (see Karemaa, 2000; Niemi, 2007) significance of Russian immigration to Finland, and the sensitivity of Finnish-Russian relations (see Nshom \& Croucher, 2014), no research has been carried out in Finland with the aim of understanding the role of perceived threat on the attitudes of Finns towards Russian immigrants. According to Mannila and Reuter (2009), studies on Russian immigration to Finland have rather focused on other issues such as psychological acculturation, ethnic identity, adaption and perceived discrimination of Russian immigrants (e.g. Jasinskaja-Lahti, 1998, 2000; Jasinskaja-Lahti et al., 1998, 2001; JasinskajaLahti, Liebkind, Jaakkola \& Reuter, 2006; Liebkind, Mannila, Jasinskaja-Lahti, Jaakkola, Kyntäjä, \& Reuter, 2004) with little or no attention to the factors that explain and predict negative attitudes towards Russian immigrants among Finns. The aim of this study is to fill this gap. First, this study examines perceived threat as a predictor of Finnish adolescent's prejudice towards Russian immigrants in the Eastern region of Finland, which is home to the highest number of Russian immigrants in the country. Second, this study explores the relationship between intergroup contact, perceived threat (realistic threat, symbolic threat, and negative stereotype), and prejudice. In order to do this, this study employs integrated threat theory (ITT) (Stephan \& Stephan, 1993, 1996, 2000) and the contact hypothesis (Allport, 1954). Stephan and Stephan's (1993, 1996, 2000) ITT provides a useful framework for understanding, explaining and predicting negative attitudes towards immigrants or minorities. It identifies realistic threat, symbolic threat, negative stereotype, and intergroup anxiety as predictors of prejudice or negative attitudes towards outgroups. Allport's (1954) contact hypothesis explains how intergroup contact could positively affect the feeling of prejudice, especially when it is cooperative, individualized, voluntary, equal status, and positive.

\section{Integrated Threat Theory (ITT)}

One of the reasons for anti-immigrant attitudes in Europe is ethnic threat perception (Schneider, 2008). Believing that people from other cultures are a threat to one's own culture and survival can negatively impact intercultural relations whether at a diplomatic, business, individual and /or interpersonal level. At a higher level, wars have been fought because of such fears because feelings of threat 
have been found to lead to prejudice and discrimination towards people from other cultures (Stephan, Diaz-Looving \& Duran, 2000). Prejudice is:

An aversive or hostile attitude towards a person who belongs to a group, simply because he belongs to that group, and is therefore presumed to have the objectionable qualities ascribed to the group... Ethnic prejudice is an antipathy based upon a faulty and inflexible generalization. It may be felt or expressed. It may be directed toward a group as a whole, or towards an individual because he is a member of that group. (Allport, 1954 p. 7).

Research has demonstrated that perceived threat has the ability to explain and predict prejudice towards immigrants and minorities (Curseu, Stoop \& Schalk, 2007; Gonzalez, Verkuyten, Weesie \& Poppe, 2008; Scheibner \& Morrison, 2009; Stephan \& Stephan, 2000; Stephan et al., 2000; Stephan, Ybarra, Martnez, Schwarzwald \& Tur-Kaspa, 1998). Basically, prejudice can be predicted by four types of threats: realistic threats, symbolic threats, intergroup anxiety, and negative stereotypes (Stephan et al., 1998; Stephan, Ybarra, \& Bachman, 1999; Stephan \& Stephan, 1996, 2000; Stephan, Boniecki, Ybarra, Bettencourt, Ervin, Jackson, McNatt \& Renfro, 2002).

Realistic threats are threats to the physical, political, and economic power of the in-group or its members (Stephan et al., 2000) and according to Schweitzer, Perkoulidis, Krome, Ludlow and Ryan (2005), realistic threat gained its origin from the realistic group conflict theory. According to Curseu, Stoop and Schalk (2007), this occurs when social groups living together in a shared context compete for scarce resources and develop conflicting goals. The core issue here is therefore presumed to be the perceived competition over scarce resources and the assumption that they are threatened by immigrants (Gonzalez et al., 2008). For example, rising unemployment in Finland has often been linked to immigrants such as Estonians and Russians (Finnish National Broadcasting Company 2011; Jaakola, 2009; Nshom \& Croucher, 2014).

Symbolic threats are threats that occur because of differences in worldview, beliefs, norms, culture, morals, values, and attitudes between the in-group and the out-group. Outgroups that adhere to a different way of life are often disliked by the in-group (Stephan et al., 2000). For example, symbolic 
threat is related to prejudice towards Muslims in the Netherlands (Gonzalez et al., 2008) and in Western Europe (Croucher, 2013).

Intergroup anxiety often occurs in the process of interaction between members of the in-group and the out-group. This anxiety happens because of the fear of being ridiculed, embarrassed, or exploited. Feelings of anxiety have been shown to be related to prejudice (Stephan et al., 1999). Croucher, Homsey, Brusch, Buyce, DeSilva \& Thompson (2013) argued intergroup anxiety is an individual level fear rather than a group level fear like the other threats. Since the focus of this study is on group level fears, intergroup anxiety is not included.

Negative stereotypes according to Lehtonen (2005) can be viewed as "generalizations that are assumed to be common among the members of a given in-group and which concern the members of a given collective, ... who are assumed to share the same attitudes, personality traits and behavioral predispositions" (p. 67). They are implied threats to the in-group because in the process of interaction, in-group members often fear negative consequences will befall them. For example if an in-group member thinks an out-group is dishonest, unintelligent or violent, they will expect interactions between them and members of the out-group to be negative and as a consequence dislike them (Stephan et al., 2000).

\section{Research hypotheses}

In Finland, studies investigating the manifestation or perception of these threats and to what extent they predict and explain prejudices particularly towards Russian immigrants are non-existent. However, Nshom and Croucher (2014) carried out a study describing how differently younger Finns feel threatened by Russian speaking immigrants from older Finns. However, the authors did not examine the extent to which these threats predicted or explained prejudice and negative attitudes towards Russian immigrants. A focus in the current study is to find out to what extent these threats (realistic threat, symbolic threat, and negative stereotypes) predict prejudice towards Russian immigrants among Finnish adolescents in the Eastern region of Finland, which houses the highest number of Russian immigrants in the country. Taking into consideration literature that suggests perceived threat is 
an effective predictor of prejudice (Stephan \& Stephan, 1993, 1996, 2000), the following research question is posed:

RQ1: To what extent does perceived threat (realistic threat, symbolic threat, and negative stereotype) predict Finnish adolescent's prejudice towards Russian immigrants?

It is also important to note that Russian immigrants have visibly been active part of Finnish history. Finland and Russia have a rather interesting history. Finland was under Russian domination and both countries fought major wars with Finland gaining its independence in 1940. Since then, Russians have traditionally and stereotypically been perceived as the archenemy and the oppressor. According to Karamaa (2004), this stereotypical perception is said to have been transferred from one generation to another and is present in Finnish society today even among Finnish adolescents. In fact, Nshom and Croucher (2014) found that adolescents in the Eastern region of Finland had as much negative stereotypes about Russian immigrants as Finns over the age of 65 . Essentially, there was no significant difference between younger and older Finns in the level of negative stereotype towards Russian speaking immigrants. Stereotypical perceptions about Russians have been considered to be the most common reason why Finns show negative attitudes towards Russians living in Finland (Karamaa, 2004). With this in mind, among the different types of threat (realistic threat, symbolic threat and negative stereotype), it is expected negative stereotype will be the strongest predictor of negative attitude or prejudice towards Russian immigrants. Thus the following hypothesis is posed:

H1: Negative stereotype will be the strongest predictor of prejudice towards Russian immigrants.

\section{Intergroup Contact}

Literature on the intergroup contact hypothesis suggests that when intergroup contact is cooperative, individualized, voluntary, equal status, and positive, it has the ability to reduce prejudice thereby improving intergroup relations (Allport, 1954). In recent decades, there has been an intense renewal of research and theoretical interest in Allport's (1954) intergroup contact hypothesis (Pettigrew \& Tropp, 2008). Brown and Hewstone (2005) and Pettigrew (1998) developed the hypothesis into a 
more refined theory and have shown its applicability in a wide variety of groups and settings. This has successfully established the basic contention that intergroup contact between the ingoup and outgroup reduces prejudice (Pettigrew \& Tropp, 2006, 2008). Many studies conducted in various situations and with several prejudiced social groups like foreign students, immigrants, refugees and the elderly have supported this notion (e.g. Jaakkola, 2000; Stephan \& Stephan 1996; Stephan et al., 1998, 2000; Valentova \& Guayarmina, 2010).

In relation to adolescents in Europe, Ford (2006) also argued adolescents will experience more social communication and contact and display more acceptance and tolerance because they grew up when the migrant group had settled in the country. He associated the possibility for adolescents to have more liberal attitudes towards immigrants by arguing a typical and average European youngster has the experience or possibility of traveling to different countries where they get in contact with people from other countries and cultures. In addition, an average Western European is educated especially with the increase in higher secondary and tertiary education in the continent. He insists they are bound to encounter a degree of social and cultural diversity within the school or the wider city. This fosters a more cosmopolitan attitude toward foreigners and immigration.

Based on Allport's contact theory (1954), Ford's proposition (2006) and the fact that Russian immigrants are the most populous immigrant group in Eastern Finland (Nshom \& Croucher, 2014), contact with Russian immigrants is expected to be high and by analyzing the quantity and quality of contact with Russian immigrants, it is expected that intergroup contact will be negatively related to the level of threat and prejudice. Thus, the following hypothesis is posed:

H2: Intergroup contact with Russian immigrants is negatively related to perceived threat and prejudice. 


\section{Method}

\section{Participants and Procedures:}

This study was carried out in the Eastern region of Finland (Joensuu) bordering Russia. This region is home to the highest number of Russian speakers. Respondents consisted of Finnish students from upper secondary to high school with an age range of 11 to 19 . Data were collected through selfadministered questionnaires and the researcher made sure it conformed to the established institutional ethical guidelines. Overall, there were 305 final participants: 188 (60\%) were women while 122 (40\%) were men. 43 participants (14.1\%) were between 11 to 13 years old (early adolescents); 182 (59.7\%) were between 14-16 (middle adolescents) and 80 (26.2 \%) were 17-19 years old (late adolescents). Since this study is interested in native Finns, all non-native Finns were disqualified from the study. The researcher obtained official authorization from the appropriate authorities and organized data collection trips to the schools. Completing the questionnaire took approximately 10 to 15 minutes and participants were not compensated for their participation. Participation was completely voluntary.

\section{Measures}

The measures in the questionnaire included demographics, a measure of symbolic threat (González et al., 2008), a measure of realistic threat (González et al., 2008), a measure of negative stereotypes (González et al., 2008), a measure of prejudice (Stephan \& Stephan 2002), and a measure of contact (both quality and quantity) adapted from González et al. (2008). The survey was originally prepared in English and then translated/back-translated into Finnish by native speakers of Finnish-English. See Table 1 for the means, standard deviations, correlations, alphas, and kappas for the study variables.

Realistic Threat: In order to measure realistic threat, participants were asked to respond to the following three statements: "Because of the presence of Russian immigrants, Finns have more difficulty finding a job", "Because of the presence of Russian immigrants; Finns have more difficulty finding a house," and "Because of the presence of Russian immigrants, unemployment in Finland is increasing." These questions were taken from González et al. (2008) and had a reliability of .80. For 
this current study, the alpha reliability for realistic threat was .94. Response categories ranged from (1) strongly disagree to (5) strongly agree. Higher scores meant more threat.

Symbolic Threat: symbolic threat was assessed by three items from González et al. (2008). These included "Finnish identity/culture is threatened because there are too many Russian immigrants today," "Finnish norms and values are threatened because of the presence of Russian immigrants today," and "Russian immigrants are a threat to Finnish culture". Response categories ranged from (1) strongly disagree to (5) strongly agree. Higher scores implied stronger feeling of threat. This scale showed an alpha reliability of .89 in the original study of González et al. (2008). In this current study the alpha reliability was .94 .

Stereotypes: Negative stereotype was assessed by asking participants to what extent some 8 trait adjectives fully described Russian immigrants. Examples of such adjectives are as follows: violent, dishonest, unintelligent, friendly, arrogant, kind, greedy, and inferior. Friendly and kind were reverse coded and higher scores meant more negative stereotypes. Responses ranged from (1) no, absolutely not, to (5) yes, certainly. The alpha reliability for these traits was .83 in the original study of González et al. (2008) but for this study it was .84

Prejudice: Prejudice was measured by presenting participants with six evaluative and emotional reactions and asking to indicate to what extent that reflected how they felt towards Russian immigrants. This scale was adapted from Stephan et al. (2002). The items that made up the scale included: Acceptance, approval, admiration, antipathy, disdain, and disrespectful. Acceptance, approval and admiration were reverse scored and an alpha reliability coefficient of .71 was obtained for prejudice in this study. Response options ranged from (1) totally disagree to (5) absolutely agree. Higher scores indicated more feelings of prejudice towards Russian immigrants.

Intergroup contact: Intergroup contact was measured using four items from González et al. (2008). Two sample items include: "How many Russian immigrant friends do you have?" and "Do you have contact with Russian immigrants?". The first item was rated from (1) none to (4) only Russian immigrant friends. The remaining three items were as follows: "Do you have contact with Rus- 
sian immigrants at school?", "Do you have contact with Russian immigrants in your neighborhood?", "Do you have contact with Russian immigrants somewhere else such as during activities? Response options ranged from (1) never to (4) often. The alpha reliability for the scale was .70 and .72 in the original study and current study respectively. Table 1 contains the means, standard deviations, alphas and correlations for all variables in this study.

Insert Table 1 here

\section{Results}

To explore $R Q 1$, a multiple regression analysis was conducted with prejudice as the dependent variable and the different types of threats (realistic threat, symbolic threat, and negative stereotype) as the independent variables. Results indicated all three types of threat: realistic $(\beta=.26, p<.05)$, symbolic $(\beta=-.27, p<.05)$, and negative stereotype $(\beta=.34, p<.0001)$ significantly predicted prejudice towards Russian immigrants: $F=12.76, p<.0001, R^{2}=.13$. See Table 2 for the full regression results. Due to a high correlation between realistic threat and symbolic threat, the test to determine if the data met the assumption of collinearity was conducted. It indicated that multicollinearity was not a concern (symbolic threat Tolerance $.26, V I F=3.75$, realistic threat, Tolerance $.26, V I F=3.75$ and negative stereotype, Tolerance $.99, \mathrm{VIF}=1.01$ ).

Insert Table 2 here

To address, H1, the three types of threat (realistic threat, symbolic threat, and negative stereotypes) were individually regressed on prejudice in order to test the predictive power of each threat in isolation from the effect of the other threats. Individually, symbolic threat was not a significant predictor of prejudice: $F=.55, p=.46, R^{2}=.002$. Individually, realistic threat was not a significant predictor of prejudice: $F=.33, p=.57, R^{2}=.001$. Individually, negative stereotype was a significant predictor of prejudice: $F=32.94, p<.0001, R^{2}=.12$. Thus, negative stereotype was the only significant threat predictor of prejudice; therefore, $H 1$ is supported. 
To address H2, which argued contact with Russian immigrants would be negatively related to threat and prejudice, a Pearson's correlation analysis was conducted. Results suggested intergroup contact was not significantly correlated with prejudice $(r=-.03, p=.63)$ nor with realistic threat $(r=$ $.09, p=.07)$, symbolic threat $(r=.08, p=.07)$ and with negative stereotypes $(r=.06, p=.16)$. Thus, H2 is not supported (see Table 1).

\section{Discussion}

This study showed perceived threat as a whole to be a significant predictor of prejudice towards Russian immigrants. Cultural differences between Russian immigrants and Finns, negative stereotypes about Russian immigrants and perceived economic difficulties posed by Russian immigrants are altogether important elements that explain negative attitudes towards Russian immigrants among Finnish adolescents. This supports the integrated threat theory of prejudice (ITT), which stipulates prejudice or negative attitudes towards immigrants and minorities can be predicted by perceived threat (Stephan \& Stephan, 1993, 1996, 1998). Research has demonstrated perceived threat has the ability to explain and predict prejudice towards outgroups (Curseu, Stoop \& Schalk, 2007; Gonzalez, Verkuyten,Weesie \& Poppe, 2008; Scheibner \& Morrison, 2009; Stephan \& Stephan, 2000; Stephan et al., 2000; Stephan, Ybarra, Martnez, Schwarzwald \& Tur-Kaspa, 1998). A case in point, Stephan, Ybarra, and Bachman (1999) studied attitudes towards three different immigrant groups (Cubans, Asians, and Mexicans) in the US and found prejudice was predicted by threat in all three immigrant groups.

However, it was observed that even though perceived threat, which is the combination of all three kinds of threat, significantly predicted a substantial amount of prejudice as indicated, individually, symbolic and realistic threat did not significantly predict prejudice towards Russian immigrants irrespective of the fact that they were the highest and most perceived threats respectively. On the other hand, even though negative stereotype was the least perceived threat compared to the other threats, this study showed negative stereotype to be the strongest and only significant predictor of prejudice towards Russian immigrants among Finnish adolescents. This result provided support for H1, which 
postulated negative stereotype would be the strongest predictor of prejudice towards Russian immigrants. Thus, among the different types of threats, negative stereotype is the only threat that is statistically important to attitudes towards Russian immigrants among Finnish adolescents in the Eastern region of Finland. There is an abundance of literature showing the perception of negative stereotype can lead to prejudice and negative attitudes towards immigrants (Stephan et al., 1998, 2000).

However, in the last decade, there also has been research questioning the conceptualization of negative stereotype as one of the four threats predicting outgroup attitudes (Stephan, Boniecki, Ybarra, Bettencourt, Ervin, Jackson, McNatt, \& Renfro, 2002). There is debate as to whether negative stereotype should be conceptualized as a predicator of threat or a predictor of negative attitudes (Riek et al., 2006). In fact, Riek et al. (2006) in their meta-analytical review of integrated threat and outgroup attitudes recommended negative stereotype and intergroup anxiety be replaced with group esteem threat. Stephan et al. (2002) in their study found negative stereotyping to be more fitted as a predicator of threat rather than negative attitudes. Similarly, Aberson and Gaffney (2008) conceptualized negative stereotypes as an antecedent of threat, rather than a threat itself. In another study, Stephan, Demitrakis and Yamada (2000) studied the attitudes of women towards men and found negative stereotypes to not be important to attitudes towards men, and Harrison and Peacock (2010) suggested negative stereotyping be removed as part of the four types of threats predicting prejudice. In fact in the most recent revisions of ITT, the original four threats (realistic threats, symbolic threats, negative stereotypes and intergroup anxiety) have been revised and reduced to two basic threats - realistic and symbolic threats (Stephan \& Renfro, 2002; Stephan, Ybarra \& Morrison, 2009; Stephan, Ybarra \& Rios, 2015). However, the ability of negative stereotype to predict prejudice and negative attitudes towards outgroups has received empirical support since the inception of ITT (Stephan et al., 1998, 2000). This study utilized the original conceptualization of ITT (Stephan \& Stephan, 1996, 1998, 2000) which includes negative stereotype because of the centrality of negative stereotype within the context of Finnish Russian relations.

The current study clearly showed negative stereotype to be the only threat significantly predicting prejudice or negative attitudes towards Russian immigrants. This study finds support for negative 
stereotype as an effective predictor of prejudice. It is also important to however acknowledge the gap in research as to the factors that affect the degree to which individual threats are likely to predict prejudice or negative attitudes.

Despite literature suggesting the extent to which perceived threats are likely to predict prejudice can depend on some factors such as: the prior historical relations between the groups, the relative status of the groups, the strength of in-group identification, knowledge of the out-group and the nature of intergroup contact (Stephan et al., 1999; Stephan \& Stephan, 2000; Stephan, Renfro, \& Davis, 2008), research explaining why some threats would be less predictive of prejudice (in this case, realistic and symbolic threat) and others more predictive of prejudice (in this case negative stereotype) in the same sample is limited. The findings in this study are rather interesting. Negative stereotype is the only threat significantly predicting negative attitudes towards Russian immigrants compared to realistic and symbolic threat. This means Finnish adolescents will less likely prejudice Russian immigrants because of economically related fear. One explanation for this is the nature of the sample. First, it is important to note this study was carried out among adolescents aged 11 to 19 , and all of them were students. People in this age category are less likely to perceive economic difficulties. They will be less likely to prejudice immigrants for taking their jobs, as this feeling of competition is less likely to arise. González et al. (2008) emphasized that for realistic threat:

The core issue here is (perceived) competition over scarce resources, such as houses and jobs, and the perception that these resources are threatened by outsiders. The desire to protect the ingroup's interests is considered the underlying motivation responsible for negative attitudes and discriminatory behavior. (p. 669).

Moreover, this study was carried out in Eastern Finland. This region borders Russia and has an economic, political and cultural interest in Russia (Nshom \& Croucher, 2014). In fact Russian immigrants are the most populous immigrant group in the region (Statistics Finland, 2014). By implication, contact with Russian immigrants and knowledge about Russian immigrants at school and in the wider city is probably high and this could be an explanation as to why cultural difference between 
Russians and Finns (symbolic threat) is not important to negative attitudes towards them. Stephan et al., (1999) stated, when "in-group members are knowledgeable about the out-group, and contact has been extensive, voluntary, positive, individualized, and cooperative, threats are unlikely to be strong predictors of prejudice" (p.2232). This is similar to the idea proposed by the contact hypothesis (Allport, 1954). Moreover, the fact symbolic threat is high among Finnish adolescents but does not significantly predict negative attitudes towards Russian immigrants, means that even though Finnish adolescents think Russian immigrants represent a threat to the Finnish culture, values and norms but it doesn't matter when it comes to disliking them. This is particularly important because this study shows symbolic threat to be negatively associated with prejudice towards Russian immigrants. One factor that may have affected and accounted for such a relationship is personal beliefs such as religious beliefs. People could sometimes perceive an outgroup as highly threatening but because of their beliefs may not be permitted or comfortable to dislike or prejudice them. Moreover even though the quality of contact experiences was not measured, it is possible that positive contact experiences might have led to lower feelings of prejudice but not lesser feelings of threat especially as the study location is home to the highest number of Russians in the country. Prejudice is an emotional state and can be easily affected by external factors that change the way we feel. But the threat pose by Russians is deeply rooted not only in the common history between Finland and Russia but also in the Finnish collective identity. Lehtonen (2005) has argued that identifying as part of an in-group is a commitment to share in the in-group's generalized perception of self "us" and "others" (Russian immigrants) (Nshom \& Croucher, 2014). This may be some of the factors influencing the nature of the relationship between symbolic threat and prejudice.

However, an interesting finding in this study is the extent to which negative stereotype is related to Finnish adolescents prejudice towards Russian immigrants. Negative stereotype is the only significant threat predicting prejudice towards Russian immigrants among Finnish adolescents. This is probably because Russian immigrants in Finland have traditionally and stereotypically been perceived as the enemy. This is primarily because Finland was under Russian domination and the common history between Finland and Russia was characterized by conflict, which gained Finland its independ- 
ence from the hands of its "Russian oppressors" (Nshom \& Croucher, 2014). This stereotypical perception of Russians according to Karamaa (2004) has been transferred from one generation to another and is present in Finish society today, even among young people. Nshom and Croucher (2014) found Finnish adolescents in Eastern Finland had as much negative stereotypes about Russian speaking immigrants as older Finns over 65 years old. There are many ways through which stereotypes can be transported to children and adolescents. It can be transported through different ways of communication such as everyday talk, cultural jokes, phrases, and conceits, the wording of news items in newspapers, cartoons, films, and TV ads, just to name a few. Communication can sometimes consciously or unconsciously contain transparent or embedded stereotypes (Lehtonen, 2005). Moreover, a lot of Russian immigrants live in this region. Negative contact experiences have the ability to enforce stereotypical perceptions and consequently lead to negative attitudes (Aberson \& Gaffney, 2008). So the common history between Finland and Russia and the generational and traditional stereotypical perception of Russians in Finland and most probably the possibility for negative contact experiences in the region (Eastern Finland) and negative media portrayal are important factors that could account for the salience of negative stereotype. This supports the idea that when prior historical relations between the in-group and the out-group have been amicable, then threats will less likely be related to prejudice (Stephan et al., 1999). This is not the case between Finns and Russians. However, this study alongside others such as Stephan et al. $(1998,2000)$ clearly show the perception of negative stereotype to be a strong predictor of prejudice and negative attitudes towards immigrants.

Moreover, this study showed there is no significant relationship between intergroup contact and prejudice and similarly between intergroup contact and threat (realistic threat, symbolic threat, and negative stereotypes). This therefore means $H 2$ was not supported. This does not support the contact hypothesis of Allport (1954) and previous research that has found intergroup contact to be related to prejudice or threat (Brown \& Hewstone, 2005; Jaakkola, 2000; Pettigrew, 1998; Pettigrew \& Tropp, 2006, 2008; Stephan \& Stephan 1996; Stephan et al., 1998, 2000; Valentova \& Guayarmina, 2010). This also raises the question of under what circumstances should intergroup contact be related to outgroup attitudes. Allport (1954) clearly emphasized how intergroup contact could affect the feeling of 
prejudice particularly when it is cooperative, individualized, voluntary, equal status, and positive.

Positive contact has been associated with lesser feelings of threat and negative attitude. It is expected positive contact will relate to reduced feeling of threat and prejudice while negative contact to increased feelings of threat and prejudice (Aberson \& Gaffney, 2008). Aberson and Gaffney (2008) in their study employed this distinction and found positive contact experiences were related to lesser feelings of threat while negative contact experiences were related to greater feelings of threat. The intergroup contact measure (González et al. 2008) used in this study mostly focused on contact frequency. There was just one question for contact quality. This definitely represents a potential limitation. Future research investigating the relationship between contact and prejudice towards outgroups should also consider and examine the nature (positive and negative) of contact experiences and not just the quantity and frequency of contact. This probably explains why this study did not find any significant relationship between intergroup contact, threat and prejudice.

\section{Implication and future research}

Russian immigration is very significant to Finland economically, politically, and culturally. This study showed realistic and symbolic threats are not important to prejudice towards Russian immigrants but negative stereotype was shown to significantly predict and explain prejudice and negative attitudes towards Russian immigrants. This necessitates interventions that will reduce the perception of negative stereotypes as this study shows it could lead to prejudice against Russian immigrants especially in schools. There is therefore a need to create anti-stereotyping programs in schools to help counter these stereotypical perceptions about Russian immigrants among Finnish adolescents. Such programs would improve Finnish-Russian relations and promote a safe educational environment for Russian speaking pupils. Whenever stereotypes are applied to members of a group, they tend to be denigrating and in most cases form the basis for intergroup prejudice. This may hinder communication, intercultural exchange/dialogue, and interpersonal relationships (Ringo, 2005). Research suggests members of the host culture are less likely to accept an immigrant group if they feel threatened. This also represents a potential hindrance to the successful adaptation of Russian speaking pupils as it is very difficult for outgroups to adapt if they are not welcomed and accepted by the members of the 
host culture (Croucher, 2013; Croucher et al., 2013; Kim, 1988; Nshom \& Croucher, 2014). Moreover, adolescence is a crucial and very important developmental stage. They represent the next generation of policy makers and it is throughout these years that prejudice and attitudes towards outgroups form and crystallize (Kiesner, Maass, Cadinu \& Vallese, 2003).

However, future research should consider the circumstances in which individual threats effectively predict prejudice. The different factors advanced by Stephan et al. (1999) and in the original conceptualization of ITT (Stephan \& Stephan, 2000) are not threat specific. These factors may not be applicable for all threats and in every situation and at the same time. There are also other factors that may mediate the relationship between perceived threat and prejudice and it is important to consider them.

This study is limited by sampling. The study used a purposive convenience sampling as it is almost impossible to achieve true random sampling in intercultural research (Nshom \& Croucher, 2014). Moreover, this study was carried out in Eastern Finland. This region borders Russia and Russian immigrants are the biggest immigrant group in the region (Statistics Finland, 2014). Since this study focused on Russian immigration and intergroup contact, this region appeared very relevant. However, generalizations to the entire Finnish population should be done with care.

This is the first study to the best of my knowledge that includes early adolescents (adolescents below 14 years old) in a study on ITT. The sample for this study consisted of adolescents from 11 to 19 years old (early, middle and late adolescents). Earlier studies applying ITT among adolescents have only focused on middle and/or late adolescents. Early adolescence is important and crucial because some studies have found a peak in prejudice from around early adolescence (e.g., Black - Gutman \& Hickson, 1996; Kiesner et al., Rutland 1999).

Until now, no studies in Finland considered exploring the extent to which perceived threat predicts or explains negative attitudes towards Russian immigrants among Finns. This study successfully and clearly demonstrated threat is a significant predictor of prejudice towards Russian immigrants in Eastern Finland. Individually, negative stereotype was found to be the only threat that significantly predicted prejudice towards Russian immigrants. Realistic and symbolic threats were not important to the 
attitudes of Finnish adolescents towards Russian immigrants. Last, this study found no significant relationship between intergroup communication / contact, prejudice and threat (realistic threat, symbolic threat, and negative stereotype. 


\section{References}

Aberson, C. \& Gaffney, A. (2008) An integrated threat model of explicit and implicit attitudes.

European Journal of Social Psychology, 39, 808-830.

Allport, G. (1954). The nature of prejudice. Cambridge MA: Addison-Wesley.

Curseu, P. L., Stoop, R., \& Schalk, R. (2007). Prejudice toward immigrant workers among Dutch employees: Integrated threat theory revisited. European Journal of Psycholo gy, 3, 125-140.

Brown, R.J. \& Hewstone, M. (2005). An integrative theory of intergroup contact. In M. Zanna (Ed.), Advances in experimental social psychology (Vol. 37, pp. 255-331). San Diego, CA: Academic Press.

Croucher, S. M. (2013). Integrated threat theory and acceptance of immigrant assimilation: An analysis of Muslim immigration in Western Europe. Communication Monographs,80, 46-62.

Croucher, S. M., Homsey, D., Brusch, E., Buyce, C., DeSilva, S., \& Thompson, A. (2013). Prejudice towards American Muslims. Journal of Intercultural Communication, 32,

http://immi.se/inter0063ultural/.

ECRI. (2007). Third report on Finland. Retrieved August 11, 2011,

fromhttp://hudoc.ecri.coe.int/XMLEcri/ENGLISH/Cycle_03/03_CbC_eng/FIN-CbC-III- 2007-23-

ENG.pdf.

Ervasti, H. (2004). Attitudes towards foreign-born settlers: Finland in a comparative perspective. In I. S. Teoksessa (Ed.), Yearbook of population research in Finland (pp. 25-

44). Helsinki, Finland: Väestöliitto, Väestöntutkimuslaitos.

Ford, R. (2012). Europe's young cosmopolitans: Explaining generational differences in immigration attitudes. University of Manchester, Institute of Social Change working paper.

González, K. V., Verkuyten, M., Weesie, J., \& Poppe, E. (2008). Prejudice towards Muslims in the Netherlands: Testing integrated threat theory. British Journal of Social Psy chology, 47, 667-685. 
Jasinskaja-Lahti, I., \& Liebkind, K. (2001). Perceived discrimination and psychological adjustment among Russian-speaking immigrant adolescents in Finland. International Journal of Psychology, 36, 174-185.

Helsingin Sanomat. (2011). International edition. Retrieved from http://www.hs.fi/english/article/Estonians +now+Finland $\%$ E2\%80\%99s+largest+immigrant+group/11 35264130988.

Jaakkola, M. (2000). Finnish attitudes towards immigrants in 1987-1999. (I. Söderling, Toim.) Helsinki, Finland: Väestöntutkimuslaitos.

Jaakkola, M. (2009). Maahanmuuttajat suomalaisten näkökulmasta. Asennemuutokset 1987-2007. Helsinki, Finland: City of Helsinki Urban Facts Research Series.

Jasinskaja-Lahti, I. (2000). Psychological acculturation and adaptation among Russian speaking adolescents in Finland. Retrieved from www.ethesis:http://ethesis.helsinki.fi/julkaisut/val/sosps/vk/jasinskaja-lahti/psycholo.pdf. Jasinskaja-Lahti, I., \& Liebkind, K. (1998). Content and predictors of the ethnic identity of Russianspeaking immigrant adolescents in Finland. Scandinavian Journal of Psychology, 39, 209-219.

Jasinskaja-Lahti, I., Liebkind, K. Jaakkola, M., \& Reuter, A., (2006). Perceived discrimination, social support networks and psychological well-being among three immigrant groups. Journal of Cross Cultural Psychology, 37, 293-311.

Karemaa, O. (2004). Foes, fiends, and vermin. Ethnic hatred of Russians in Finland 1917-1923. Retrieved from http://finoved.madistudio.com/?idm=41\&op=main\&idcont=126.

Kiesner, J., Maass, A., Cadinu, M., \& Vallese, I (2003). Risk factors for prejudice attitudes during early adolescence. Social Development, 12, 288-308.

Kim, Y. Y. (1988). Communication and cross-cultural adaptation: An integrative theory. Clevedon, UK: Multilingual Matters. 
Kyntäjä, E. (1997). Ethnic remigration from the former Soviet Union to Finland-patterns of ethnic identity and acculturation among the Ingrian Finns. In S. S. Teoksessa (Ed.), Yearbook of population research in Finland (pp. 102-113). Helsink, Finland: Väestöliitto, Väestöntutkimuslaitos.

Lehtonen, J. (2005). Stereotypes and collective identification. In: Cultural Identity in an intercultural context (pp. 67-94), D. Petkova \& J. Lehtonen (Eds.). Jyväskylä, Finland: University of Jyvaskyla.

Liebkind, K., Mannila, S., Jasinskaja-Lahti, I., Jaakkola, M., Kyntäjä, E., \& Reuter, A. (2004). Venäläinen, virolainen, suomalainen. Kolmen maahanmuuttajaryhmän kotoutuminenSuomeen (Russian, Estonian, Finnish: Integration of Three Immigrant Groups in Finnish Society), Helsinki, Finland: Gaudeamus.

Mannila, S., \& Reuter, A. (2009). Social exclusion risks and their accumulation among Russianspeaking, ethnically Finnish and Estonian immigrants to Finland. Journal of Ethnic and Migration Studies, 35, 939-956.

Meuleman, B., Davidov, E. \& Billiet, J. (2009). Changing attitudes toward immigration in Europe, 2002-2007: A dynamic group conflict theory approach. Social Science Research, 38, 352-355.

Niemi, H. (2007). Russian immigrants in Finnish society. Retrieved from $\underline{\text { http://www.socmag.net/?p=270 }}$

Nshom, E. \& Croucher, S. M. (2014). Threats and attitudes toward Russian-speaking immigrants: A comparative study between younger and older Finns. Russian Journal of Communication, 6, 308-317. Pettigrew, T. F., \&Tropp, L. R. (2008). How does intergroup contact reduce prejudice? $\quad$ Me $\quad$ taanalytic tests of three mediators. European Journal of Social Psychology, 38, 922- 934.

Pettigrew, T. F., \& Tropp, L. R. (2006). A meta-analytic test of intergroup contact theory. Journal of Personality and Social Psychology, 90, 751-783.

Pettigrew, T. F. (1998). Intergroup contact theory. Annual Review of Psychology, 49, 65-85. 